\title{
The Sesquicentennial Celebration of the American Psychiatric Association
}

\author{
Sydney Brandon
}

The annual meeting of the American Psychiatric Association is always something of a jamboree but this year its Sesquicentennial Celebration (1844-1994), held in its birthplace Philadelphia PA, was especially splendid with a birthday gala held in the elegant and richly endowed Art Gallery. However, attendance at the Philadelphia meeting was disappointing with only 15,000 delegates.

Held over five days at no time between 6.30 am and $10.00 \mathrm{pm}$ were there less than 30 or 40 sessions to choose from. These ranged from the most recent developments in brain imaging through computing, epidemiology, ethics, human rights, the most up to date developments in psycho-pharmacology and all that is best in neuroscience to creativity and the arts, gender issues, and recovered memories.

There were many meetings on the health 'reforms' with even the Clinton Bill taking second place to the angst related to current issues in 'managed care'. The HMOs (Health Maintenance Organisations) operate a powerful stranglehold on practitioners deciding who may treat their patients, for how long and with what treatments. Even our most belligerent trust managers seem docile by comparison. Senior politicians, film stars and distinguished authors queued up to present readings of their prose and poetry or messages of support for the inclusion of psychiatric care in the new Bill.

When I first attended an APA meeting many years ago there was a message centre where one could leave notes in cubby holes. There are now three constantly rotating screens, each carrying a third of the alphabet, and sets are strategically situated in various places. They are easily recognised because each is surrounded by a group of apparently mesmerised delegates.

In Britain we have had an epidemic of counsellors who appear whenever a door is opened. The USA has psychotherapists. These are of all persuasions and training and some of the more persuasive appear to have no training at all. 'Entity therapists', 'recovered memory therapists' and multiple personality centers have been causing particular excitement, especially to the lay press, by enabling people to recover memories of childhood sexual abuse, often after many years. One 63-year-old woman charged her 85-year-old father with sexually abusing her from the age of 8 years to her early teens. These memories are 'recovered' by hypnosis or amytal interviews often in the course of intensive, expensive and prolonged therapy.

Very recently a father accused of incest by his adult daughter after she entered therapy successfully sued her therapist for creating the false memory which cost him his family and his job. He was awarded $\$ 500,000$ and this has caused some intense reappraisal.

I attended two half day sessions which might have been from different worlds. In one we were solemnly assured that society uses children as the 'poison container' and that $80 \%$ have been sexually abused before the age of six years. The other session helped restore my faith in the common sense even of psychiatrists and argued persuasively that many adults with recovered memories have been virtually brainwashed by therapists with eccentric ideologies. There was wide agreement that the 'entity therapists', particularly those who subscribed to the view that much satanic abuse and most child sex abuse is perpetrated as a consequence of alien abduction were such zealots. They believe parents have been programmed by extra terrestrials to rape their children, then the ET use highly sophisticated scientific techniques to blot out the memories. A book describing first-hand accounts of alien abduction is currently climbing the best seller lists. Apparently some of these therapists are concerned that secret government agencies spy upon them in case they learn too much of the widespread activities of aliens.

Multiple personality disorder is claimed to be a common consequence of child sexual abuse but in this session it was generally agreed to be largely an iatrogenic phenomenon. When called upon to comment on the occurrence of MPD in 
Britain, I replied that we do not allow it. Sadly this weird therapeutic activity distracts attention from the reality of child sexual abuse and brings discredit to psychiatry.

The meeting is the annual refresher for American psychiatrists and there are many opportunities for high quality continuing medical education credits which must be completed in order to retain registration. I obtained some of my credits by watching the film 'A Tribute to Charlie Parker. Jazz Musician.' He was after all a drug addict. Most of the points were hard earned with 6.30 am breakfast meetings and densely packed sessions of hard science. The meeting was a remarkable and truly American experience. It contained the best and the weirdest - but never mind the width - feel the quality.

Sydney Brandon, Emertus Professor of Psychiatry, University of Leicester, Clinical Sciences Bullding, Letcester Royal Infirmary, PO Box 65. Leicester LE2 $7 L X$

\title{
Pseudopatients in pharmacies
}

\section{Letter from Brazil}

\author{
John Dunn
}

In 1973 Professor D.L. Rosenhan published his classic paper 'On Being Sane in Insane Places' (Rosenhan, 1973). In this study eight 'normal' researchers presented themselves on 12 separate occasions to a range of psychiatric hospitals in the USA. These 'pseudopatients' complained of one symptom only, that of hearing a voice saying 'empty', 'hollow' and 'thud'. No other psychiatric symptoms were described; the pseudopatients gave their own 'normal' personal histories and after admission to hospital the researchers ceased simulating any symptoms and apart from taking notes on their experiences acted normally.

The results of the study were shocking; not only were the researchers admitted to hospital on all 12 occasions, but all bar one received a diagnosis of schizophrenia, albeit 'in remission'. Many received medication and the average length of stay in hospital was 19 days (range 7 to 52). Reading the article 20 years on, it still induces a strong reaction. One feels disbelief that the psychiatrists were so easily duped and sheer incredulity that they consistently diagnosed schizophrenia on such minimal evidence.

The study did much to undermine confidence in psychiatric services in the USA, in particular the validity and reliability of psychiatric diagnosis in the 1960s and early '70s and along with the works of Thomas Szasz and R.D. Laing added fuel to the fire of the anti-psychiatric movement.

The use of pseudopatients in research and more recently in television documentary exposés continues, sometimes with equally dramatic results. The reporter Duncan Campbell's exposure of the quack private treatment offered to people with HIV and AIDS in the Harley Street area of London is a vivid contemporary example. The method has also been used extensively in Brazil to study the widespread problem of dispensing prescription-only medication to patients without a prescription. Two particular studies illustrate the nature of this problem.

In the first study 101 third year medical students went to different pharmacies in 35 neighbourhoods in São Paulo, simulating of one of five predetermined symptoms: anxdety, feeling sleepy, insomnia, a wish to lose weight and having a family member with an alcohol problem (Carlini \& Masur, 1986). The students presented their problem to the first pharmacy assistant who was available. In $97 \%$ of cases the students were sold a medication by the assistant, $75 \%$ of preparations were prescription-only medicines and $46 \%$ contained psychotropic drugs including, benzodiazepines, amphetamines and disulfiram. Only $17 \%$ were alerted to the possibility of side-effects, sometimes with incorrect information, and just $8 \%$ were advised to seek treatment elsewhere as well. One student whose complaint was of having an alcoholic relative, was sold disulfiram and told to put it in the person's food or drink without his knowledge!

The second study took place in Porto Alegre, in the south of Brazil, and was performed by five researchers who visited 44 pharmacies complaining of one of five physical allments: sore 